\section{WATER RESOURCES}

\section{Costs and benefits}

Proc. Natl Acad. Sci. USA

http://doi.org/6nm (2015)

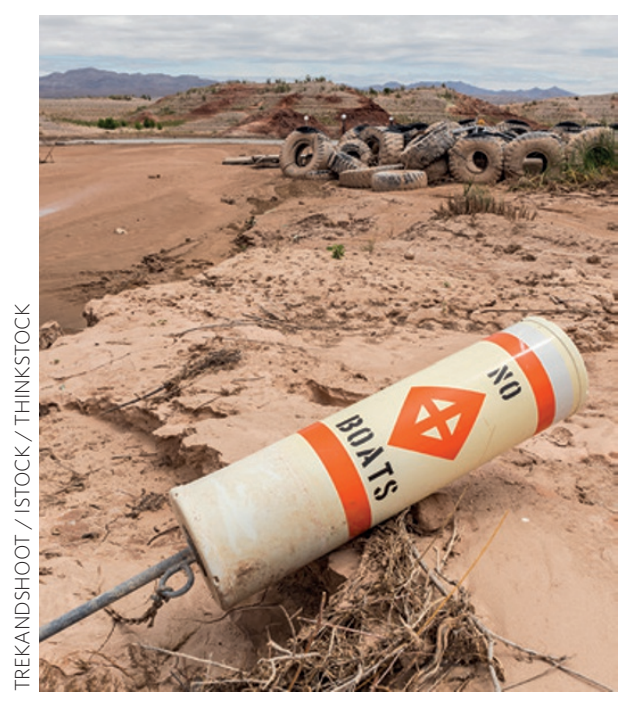

Global warming is expected to increase evapotranspiration and surface drying in many regions, which could enhance drought intensity and duration. From a water resources perspective, however, it remains unclear whether mitigating warming will reduce water stress more than these mitigation activities enhance it.

Mohamad Hejazi, from the Joint Global Change Research Institute at the Pacific Northwest National Laboratory, and co-workers use assessment models of human and natural system processes to investigate the synergies and antagonisms between climate, energy and water management/ policy in the United States. They find that - under the socioeconomic scenario investigated - reductions in water stress from climate change mitigation were less than the increase caused by emissions mitigation activities.

Although the findings are not predictive, they do show that successful policies to mitigate climate change that are not designed to preserve water resources could still enhance the severity, frequency and areal extent of water stresses.

\section{BIOGEOCHEMISTRY}

\section{Soil carbon trends}

Glob. Change Biol. http://doi.org/6nn (2015)

Soils contain the largest carbon stock in the terrestrial biosphere, so their response to climate change is important. However, soil carbon responses to warming from both modelling and experimental studies are mixed, and the net effect remains unclear.

To investigate recent trends in soil carbon dynamics, Leiyi Chen, from the Chinese Academy of Sciences, and co-workers compiled measurements from $\sim 100$ experimental studies on sites with constant land use. They found an overall increase in soil carbon content over the past few decades, with an average accumulation rate of $0.19 \% \mathrm{yr}^{-1}$. This average conceals the variability between sites, with carbon increases in $43.1 \%$, stability in $31.4 \%$, and decreases in carbon for $25.5 \%$. Soil carbon increases tended to occur in forests and grasslands (driven by a range of factors that lead to increases in biomass production) and decrease in croplands (related to changes in management such as reduced manure application and increased ploughing depth). These findings suggest that climate change has not yet resulted in soil carbon loss and is unlikely to trigger a strong positive climate feedback. $A B$

\section{CLIMATE POLICY}

\section{Joined-up thinking} J. Environ. Plann. Manage. http://doi.org/6nq (2015)

When it comes to garnering public support for policies, context matters. The public doesn't tend to care much about climate change when other global issues such as terrorism or the economy are considered in isolation. But, in reality, climate change policies compete with other social goods for public resources.

Carmelo León and Jorge Araña, from the Universidad de Las Palmas de Gran Canaria, Spain, explored how the public's valuation of climate policy changed when it was presented alongside a suite of other public policies. They conducted a study of 500 adults in Spain to assess people's preferences for alternative public policies.

People valued climate policies more highly when presented together with those concerning forest fires and development. This wasn't the case when climate policies were linked to programmes tackling terrorism or addressing oil spills. People were also more likely to value climate policy when it was part of a suite of at least three policies, regardless of what the other schemes were.

Understanding how competing options are perceived in this more-realistic setting is crucial for the development and implementation of successful climate policy.

\section{CLIMATE CONNECTIONS Heatwave forcings \\ Clim. Dynam. http://doi.org/6np (2015)}

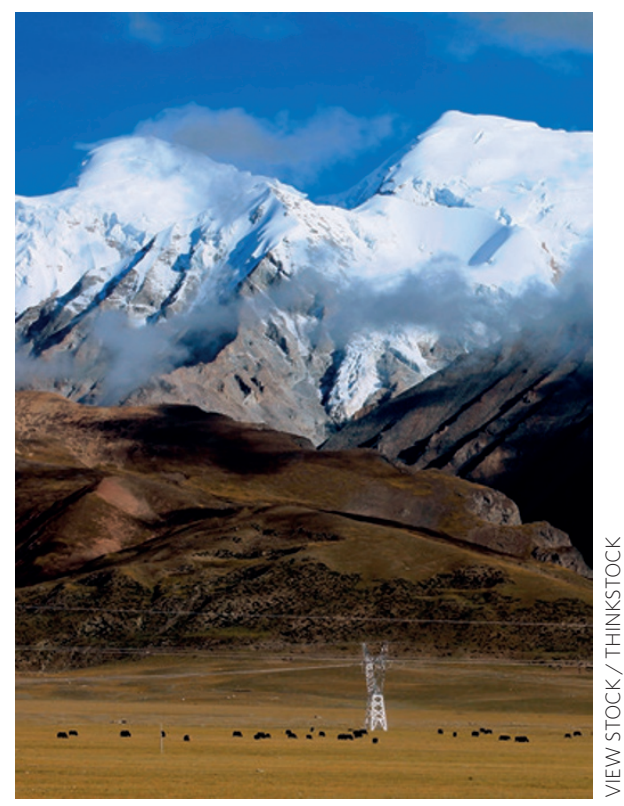

Recent summer heatwaves in Eurasia have caused significant water shortages as well as a large number of deaths. But the mechanism behind the year-to-year variability of these extreme weather events is not fully understood.

Zhiwei Wu, from Nanjing University of Information Science and Technology, China, and colleagues show that decreasing snow cover in the Tibetan Plateau could be playing an important role. They performed a set of numerical experiments with a global circulation model to examine the effect of varying snow cover in the plateau on heatwaves in Eurasia.

The authors identified a set of climate anomalies that are related to each other over large distances - a teleconnection pattern - prevailing over the mid- and high latitudes of Eurasia. Reduced snow cover on the Tibetan Plateau triggers the teleconnection, resulting in high-pressure anomalies over southern Europe and northeastern Asia. These high atmospheric pressures are associated with low cloud cover, which increases the radiation reaching the land surface, favouring more heatwaves in these regions.

With the expected decrease of Tibetan Plateau snow cover in the future, this teleconnection may be increasingly important in the development of heatwaves in Eurasia.

Written by Alastair Brown, Mat Hope and Eithne Tynan. 